OPEN ACCESS

Edited by:

Sudhir Thakurela,

Harvard University, United States

Reviewed by:

Dadi Gao,

Harvard Medical School,

United States

Dongbo Yu,

University of Chicago,

United States

${ }^{*}$ Correspondence:

Apiwat Mutirangura

mapiwat@chula.ac.th

tThese authors have contributed equally to this work.

Specialty section: This article was submitted to Epigenomics and Epigenetics,

a section of the journal

Frontiers in Genetics

Received: 03 April 2019 Accepted: 18 June 2019

Published: 04 July 2019

Citation:

Chalertpet K, Pin-on P, Aporntewan C, Patchsung $M$, Ingrungruanglert $P$, Israsena N and Mutirangura A (2019) Argonaute 4 as an Effector Protein in RNA-Directed DNA Methylation in Human Cells.

Front. Genet. 10:645. doi: 10.3389/fgene.2019.00645

\title{
Argonaute 4 as an Effector Protein in RNA-Directed DNA Methylation in Human Cells
}

\begin{abstract}
Kanwalat Chalertpet ${ }^{1+}$, Piyapat Pin-on 1,2t, Chatchawit Aporntewan ${ }^{3 \dagger}$, Maturada Patchsung ${ }^{1,4}$, Praewphan Ingrungruanglert ${ }^{5}$, Nipan Israsena ${ }^{5}$ and Apiwat Mutirangura ${ }^{4,6 *}$
\end{abstract}

\begin{abstract}
${ }^{1}$ Interdisciplinary Program of Biomedical Sciences, Faculty of the Graduate School, Chulalongkorn University, Bangkok, Thailand, ${ }^{2}$ Faculty of Medicine, King Mongkut's Institute of Technology Ladkrabang, Bangkok, Thailand, ${ }^{3}$ Department of Mathematics and Computer Science, Faculty of Science, Chulalongkorn University, Bangkok, Thailand, ${ }^{4}$ Center of Excellence in Molecular Genetics of Cancer and Human Diseases, Department of Anatomy, Faculty of Medicine, Chulalongkorn University, Bangkok, Thailand, ${ }^{5}$ Stem Cells and Cell Therapy Research Unit, Faculty of Medicine, Chulalongkorn University, Bangkok, Thailand, ${ }^{6}$ Department of Anatomy, Faculty of Medicine, Chulalongkorn University, Bangkok, Thailand
\end{abstract}

DNA methylation of specific genome locations contributes to the distinct functions of multicellular organisms. DNA methylation can be governed by RNA-dependent DNA methylation (RdDM). RdDM is carried out by endogenous small-RNA-guided epigenomic editing complexes that add a methyl group to a precise DNA location. In plants, the Argonaute 4 (AGO4) protein is one of the main catalytic components involved in RdDM. Although small interfering RNA or short hairpin RNA has been shown to be able to guide DNA methylation in human cells, AGO protein-regulated RdDM in humans has not yet been evaluated. This study aimed to identify a key regulatory AGO protein involved in human RdDM by bioinformatics and to explore its function in RdDM by a combination of AGO4 knockdown, Alu small interfering RNA transfection, AGO4-expressing plasmid transfection, chromatin immunoprecipitation, cell-penetrating peptide-tagged AGO4 combined Alu single-guide RNA transfection, and methylation analyses. We found that first, human AGO4 showed stronger genome-wide association with DNA methylation than AGO1-AGO3. Second, endogenous AGO4 depletion demethylated DNA of known AGO4 bound loci. Finally, exogenous AGO4 de novo methylated the bound DNA sequences. Therefore, we discovered that AGO4 plays a role in human RdDM.

Keywords: human Argonaute 4, human RNA-directed DNA methylation, human RdDM, CPP-AGO4, epigenomic editing

\section{INTRODUCTION}

DNA methylation plays critical regulatory roles in both of prokaryotic (Adhikari and Curtis, 2016) and eukaryotic (Tang et al., 2012; Zhang et al., 2018) organisms, including mammals (Jones and Takai, 2001). In humans, specific methylation controls cellular processes involved in many characteristics of multicellular organisms, such as tissue-specific expression and differentiation (Khavari et al., 2010; Wan et al., 2015), genomic imprinting, X-chromosome inactivation (Chen and Li, 2006; Fedoriw et al., 2012), and silencing of transposable element transcription (Hollister and Gaut, 2009; Rerkasem et al., 2015; Anwar et al., 2017). For the past decade, a connection has been reported between small RNAs and specific DNA methylation modifications, which results in transposable element control 
and genomic stability through RNA-mediated transcriptional gene silencing (Morris, 2008; Moazed, 2009).

RNA-mediated transcriptional gene silencing, a fundamental mechanism in the regulation of gene expression, has been extensively studied over the past several years. One mechanism of RNA-mediated transcriptional gene silencing is RNA-directed DNA methylation (RdDM), which was first discovered in plants and described as noncoding RNA-mediated epigenetic modification (Wassenegger et al., 1994). Studies in plants have found that one of the key proteins playing a role in $\mathrm{RdDM}$ is Argonaute 4 (AGO4) (He et al., 2009; Lahmy et al., 2016). RdDM has been further explored in humans, and it has been revealed that many varieties of small noncoding RNAs, such as small interfering RNA (siRNA) and short hairpin RNA (shRNA), can contribute to RdDM (Morris et al., 2004; Castanotto et al., 2005; Patchsung et al., 2018); however, the process has not been well characterized. Here, we investigated whether human AGO4 has a plant-like $\mathrm{RdDM}$ function and hypothesized that the human AGO4 protein might be involved in an increase in DNA methylation levels that participates in RdDM.

Mechanistically, RdDM is mainly involved in the biogenesis of 24-nucleotide siRNAs and the loading of single-guide RNAs (sgRNAs) onto the AGO4 protein. sgRNA-bound AGO4 then recruits DRM2 to promote de novo methylation at sites of sgRNA homology (Zilberman et al., 2003; Xie and Yu, 2015). Hence, to investigate RdDM pathways in humans, we initially focused on identifying the AGO protein that affects RdDM and validating the results in AGO-binding genes. The human AGO subfamily is composed of AGO1 to AGO4, each of which exhibits different functions, abundances, and levels of expression in cells (Sasaki et al., 2003; Schürmann et al., 2013). Notably, the structures of these proteins are similar and are mostly conserved; their structures are composed of N-terminal domains (involved in RNA cleavage), PAZ domains (which bind to the 3'-ends of small RNAs), MID domains (which function in small RNA loading and bind to the 5'-ends of small RNAs), and PIWI domains (containing RNase $\mathrm{H}$-like active sites for RNA cleavage) (Swarts et al., 2014).

However, some distinctions of human AGO have been noted. AGO4 differs in a few amino acid sequences from the $\mathrm{N}$-terminal and PIWI domains of AGO2, which has been well described with respect to its structure and function. AGO4 does not exhibit catalytic cleavage activity (Hauptmann et al., 2014), and the quantity of AGO4 and its expression at both the mRNA and protein levels are the lowest among its protein family (Valdmanis et al., 2011; Turchinovich et al., 2016).

Interspersed repetitive sequences consisting of the long and short interspersed elements (LINEs and SINEs) were chosen for primary observation according to a previous study showing that siRNA produced from inverted repeats and the AGO4 protein can cause maintenance of DNA methylation in plants (Zilberman et al., 2004). Moreover, studies in humans have found that LINE-1, from which bidirectional transcripts are produced to form siRNA, can suppress LINE-1 retrotransposition through DNA methylation (Yang and Kazazian, 2006; Chen et al., 2012). Nevertheless, Alu siRNA transfection can also induce Alu methylation (Patchsung et al., 2018).
In the current study, we performed a genome-wide association study and revealed that human AGO4 colocalizes to sites of promoter methylation. Furthermore, we investigated DNA methylation changes under conditions in which the AGO4 protein was depleted or upregulated. Our findings would help to extend the understanding of epigenetic pathways in humans.

\section{MATERIALS AND METHODS}

\section{Colocalization Between Promoter Methylation and Argonaute Proteins}

We performed a whole-genome colocalization analysis between a promoter methylation dataset (GSE20598) (Komashko and Farnham, 2010) and AGO-binding sites (CLIPZ database) (Khorshid et al., 2010). The GSE20598 dataset provided the amount of promoter methylation data in human embryonic kidney (HEK293) cells. The CLIPZ database provided AGObinding locations in the same cell line. Based on these two sources of data, the correlations between promoter methylation and AGO proteins were identified.

\section{GSE20598 Dataset}

The GSE20598 dataset was obtained through employed chromatin immunoprecipitation (ChIP)-chip promoter microarray (GPL6603) analysis based on the HG17 genome build. Only one sample (GSM517330), consisting of 5-meC MeDIP DNA from HEK293 cells treated with 50\% acetic acid (control), was used in our analysis. A total of 15 methylation probes were assigned to each gene and were tiled over approximately $1.5 \mathrm{~kb}$ across a promoter. The probes were $50 \mathrm{bp}$ in length. The amount of methylation at a promoter was determined from the summary of all 15 probes.

\section{CLIPZ Database}

The CLIPZ database lists all the known binding sites of AGO proteins in the entire genome of HEK293 human embryonic kidney cells. The database contains two important files: mapped sequences of RNA sequences bound by Argonaute proteins (AGO1-4) and genomic maps of the locations of these RNA sequences in the whole genome.

Mapping began at chromosome 1 and was stopped for RNA sequences that could be mapped to $>30$ locations (mostly repeat sequences). The AGO protein family members are AGO1, AGO2, AGO3, and AGO4. We downloaded the following files from http://test.mirz.unibas.ch/smirnaWeb/geneBio/smiRNA/ temp/10544043421949953483/samples in the following subfolders (October, 2011):

\begin{tabular}{|c|c|}
\hline $\begin{array}{l}\text { AGO1: } \\
\text { genon }\end{array}$ & $\begin{array}{l}/ 230 / \mathrm{mapped} \text { _s equences }, / 230 / \\
\text { appings }\end{array}$ \\
\hline $\begin{array}{l}\text { AGO2: } \\
\text { genon }\end{array}$ & $\begin{array}{l}/ 238 / \mathrm{mapped}_{-} \text {sequences }, / 238 / \\
\text { appings }\end{array}$ \\
\hline $\begin{array}{l}\text { AGO3: } \\
\text { genon }\end{array}$ & $\begin{array}{l}\text { /239//mapped_s equences, / } 239 / \\
\text { appings }\end{array}$ \\
\hline AGO4: & $\begin{array}{l}\text { / } 240 / \text { mapped_sequences, / } 240 / \\
\text { appings }\end{array}$ \\
\hline
\end{tabular}




\section{LiftOver Tool}

The ChIP-chip promoter microarray used in GSE20598 was based on the HG17 genome build, whereas the CLIPZ database was based on the HG18 genome build. Therefore, the genomic locations from HG17 were converted to locations from HG18 using LiftOver software (http://genome.ucsc.edu/cgi-bin/hgLiftOver).

\section{NimbleScan Software}

In the GSE20598 dataset, the methylation level at each promoter was summarized to a single value. In fact, the microarray used a total of 15 probes tiled over a promoter. To assess the methylation level of each probe, the supplementary file (GSE20598_RAW. tar) from Gene Expression Omnibus was needed (Barrett et al., 2009). NimbleScan software (version 2.6) from the manufacturer of the microarray (Roche NimbleGen) was used to process the supplementary file (http://www.nimblegen.com/downloads/ support/NimbleScan_v2p6_UsersGuide.pdf).

\section{Promoter Selection}

Only promoters that were bound with only one type of AGO protein (AGO1 or AGO2 or AGO3 or AGO4) were considered in our analysis to avoid any possible interactions between AGO proteins. The boundary of a promoter was defined as the region between the first and the 15th (the last) probes of each promoter.

\section{Distance Between Argonaute Binding Sites and Methylation Sites}

Both AGO-binding sites and methylation sites (or probes) were considered as numerical ranges in base pair. The distance between these sites was defined as the distance between the centers of two ranges. Each probe could contain multiple CpG sites, but the distribution of $\mathrm{CpG}$ sites on all probes was symmetric. Thus, we assumed that the methylation sites were located at the center of the probes.

\section{Association of Argonaute-Binding Sites and Methylation Levels}

The association between AGO-binding sites and methylation levels was identified by $2 \times 2$ contingency tables. A contingency table counted the number of methylation probes. The first and the second column counted the number of probes with high (MET+) and low (MET-) methylation levels. The first and the second rows counted the number of probes that were in proximity with AGObinding sites $(\mathrm{AGO}+)$ and the probes that were in AGO-depleted regions (AGO-). Each contingency table yielded odds ratio (OR), 95\% confidence interval (CI), and a Chi-squared $p$-value.

\section{Establishment of AGO4sh and Tetracycline Resistance Knocked-Down Cell Lines}

To generate a lentivirus vector encoding AGO4sh, a doublestranded AGO4sh (target sequence 5'-GGCCAGAACTAATAG CAATT-3') was cloned into $\mathrm{pENTR}^{\mathrm{TM}} / \mathrm{H} 1 / \mathrm{TO}$ (Invitrogen, CA, USA) and subcloned into the pLenti4/BLOCK-iT ${ }^{\mathrm{TM}}$-DEST
Gateway ${ }^{\circledR}$ Vector (Invitrogen) using LR Clonase ${ }^{\circledR}$ II (Invitrogen). Lentiviruses expressing AGO4sh and tetracycline resistance (TetR) were generated according to the manufacturer's instructions. Briefly, 293FT cells were transfected with $5 \mu \mathrm{g}$ of pLenti4/H1/TO/ shAGO4 (for AGO4sh), pLenti6/TR (for TetR), and $5 \mu \mathrm{g}$ of each packaging plasmid (pLP1, pLP2, and pVSV-G) (Invitrogen) using the FugeneHD transfection reagent (Roche, Basal, Switzerland). After transfection for $48 \mathrm{~h}$, the media were collected and filtered through a $0.45-\mu \mathrm{m}$-pore-size filter. The virus-containing supernatants were centrifuged at 25,000 rpm for $90 \mathrm{~min}$. Viral pellets were resuspended with Opti-MEM (Invitrogen). HEK293 cells were transduced with lentivirus-expressed shAGO4 and TetR and supplemented with $6 \mu \mathrm{g} / \mathrm{ml}$ polybrene (Sigma-Aldrich, MO, USA). After transduction for $48 \mathrm{~h}$, the cells were dissociated and seeded in $10-\mathrm{cm}^{2}$ dishes at $10 \%$ confluence. The cells were then cultured under Zeocin ${ }^{\mathrm{TM}}(100 \mu \mathrm{g} / \mathrm{ml})$ (Thermo Scientific, MA, USA) selection for 3 weeks. Zeocin ${ }^{\mathrm{TM}}$ and blasticidin-resistant clonal isolates were tested for AGO4sh activity in a tetracyclineregulated manner using real-time PCR. HuSH shRNA plasmid, pGFP-C-shLenti plasmid (Origene, MD, USA) was used as a plasmid control according to the manufacturer's instructions.

\section{Cell Culture and Treatment}

For the AGO4sh and TetR knockdown cell lines, AGO4shregulated HEK293 cells were maintained in Dulbecco's modified Eagle's medium (DMEM) (Thermo Scientific) supplemented with $2 \mathrm{mM}$ L-glutamine (Sigma-Aldrich), 10\% (v/v) heat-inactivated fetal bovine serum (FBS) (Thermo Scientific), $10 \mathrm{mg} / \mathrm{ml}$ antibiotic/ antimycotic (Thermo Scientific), $500 \mu \mathrm{g} / \mathrm{ml}$ zeocin at $37^{\circ} \mathrm{C}$, and $5 \%(\mathrm{v} / \mathrm{v}) \mathrm{CO}_{2}$. To knock down AGO4 protein expression, AGO4sh-HEK293 cells were treated with $2 \mu \mathrm{g} / \mathrm{ml}$ tetracycline for 9 days (Tet on or Tet+). AGO4sh-HEK293 cells (not treated with tetracycline or Tet off or Tet-) were also harvested on seventh and ninth day. Media and tetracycline were changed every 3 days later. All cultures were treated with 5'-azacytidine (5-AC) (Sigma-Aldrich) on days 7 to 9 , which was changed every day. Cell cultures of the HeLa cervical adenocarcinoma cell line were purchased from the American Type Culture Collection (ATCC, VA, USA). These cells were cultured in DMEM containing 10\% FBS (Thermo Fisher Scientific) and 1\% antibiotic-antimycotic (Thermo Scientific) in a $5 \% \mathrm{CO}_{2}$ incubator.

\section{Protein Preparation and Western Blot Analysis}

AGO4- and PC-overexpressing HeLa cells were harvested as whole cell lysates using radio immunoprecipitation assay lysis buffer (Amresco, OH, USA). The cells were further sonicated at a $30 \%$ amplitude for $5 \mathrm{~s}$, which was repeated three times. Then, the protein concentration was determined by using a BCA Protein Assay Kit (Thermo Scientific) according to the manufacturer's instructions. Forty micrograms of whole cell lysate was subsequently used for sodium dodecyl sulfate (SDS) polyacrylamide gel electrophoresis and Western blot analysis as previously described (Fuks et al., 2000). The antibodies employed in these assays were 1:1,000 eLF2C4 (C-12) (SC-32665) (Santa Cruz, CA, USA), 1:5,000 goat anti-mouse IgG-HRP (SC-2005) (Santa Cruz), and an anti-beta actin antibody 
[AC-15] (HRP) (Ab49900) (Abcam, Cambridge, UK). Each antibody was diluted in the $\mathrm{Bl} \varnothing \mathrm{k}^{\circledR}$ Noise Cancelling Reagent (Merck Millipore, MA, USA). Finally, the signals were visualized using the SuperSignal ${ }^{\circledR}$ west femto chemiluminescent substrate (Thermo Scientific) on a C-DiGit ${ }^{\circledR}$ blot scanner (LI-COR Biosciences, NE, USA).

\section{Chromatin Immunoprecipitation}

To detect AGO4 protein-binding genes, ChIP was performed as previously described with some modifications (Boyd and Farnham, 1999). Cells were fixed with $1 \%$ final concentration of formaldehyde for $30 \mathrm{~min}$ at room temperature, and then glycine was added at a final concentration of $0.125 \mathrm{M}$ for $5 \mathrm{~min}$ at room temperature to stop the reaction. Next, the cells were washed twice with $1 \mathrm{X}$ protease inhibitor (Thermo Scientific) containing cold phosphate-buffered saline and collected using cell scrapers. Thereafter, the cells were sonicated at a $30 \%$ amplitude five times; the supernatant was collected by centrifugation and diluted using ChIP dilution buffer. Protein A or G plus-agarose (Santa Cruz, CA, USA) was added to the samples for $1 \mathrm{~h}$ at $4^{\circ} \mathrm{C}$ on a rotating shaker for preclearing, and the supernatant was harvested to perform immunoprecipitation using $10 \mu \mathrm{g}$ of each of the HA-probe (Y-11) (SC-805) (Santa Cruz) and normal rabbit IgG (\#2729) (Cell Signaling, MA, USA) antibodies. Protein A or G plus agarose was added again to precipitate the antigen-antibody complexes, and the precipitated complexes were washed with 150 and $500 \mathrm{mM}$ sodium chloride $(\mathrm{NaCl})$ and lithium chloride buffer, respectively. The complexes were then decrosslinked, and the DNA was precipitated using ethanol and purified by phenolchloroform DNA extraction. Finally, the DNA was used for further experiments consisting of real-time PCR or conventional PCR.

\section{DNA Preparation and Sodium Bisulfite Treatment for Methylation Detection}

Cells were harvested by trypsinization, and their DNA was extracted using $10 \%$ sodium dodecyl sulfate (SDS) (Sigma-Aldrich), lysis buffer II $(0.75 \mathrm{M} \mathrm{NaCl}, 0.024 \mathrm{M}$ ethylenediaminetetraacetic acid at $\mathrm{pH}$ 8), and $20 \mathrm{mg} / \mathrm{ml}$ proteinase $\mathrm{K}$ (USB, $\mathrm{OH}, \mathrm{USA}$ ); the cells were incubated at $50^{\circ} \mathrm{C}$ for three nights for cell digestion. Phenol/ chloroform extraction and ethanol precipitation were then carried out as previously described (Sambrook, 1989). Next, $750 \mathrm{ng}$ of each DNA sample was subjected to sodium bisulfite treatment using the EZ DNA methylation-Gold ${ }^{\mathrm{TM}}$ kit (Zymo Research, CA, USA) according to the manufacturer's instructions. The eluted DNA was subsequently used for pyrosequencing or combined bisulfite restriction analysis (COBRA).

\section{Pyrosequencing to Determine DNA Methylation Levels}

Sodium bisulfite-treated DNA was used to perform PCR to enrich the DNA template for pyrosequencing (Colella et al., 2003). Pyrosequencing was carried out using the PyroMask ${ }^{\circledR}$ Gold Q24 machine (Qiagen, Hilden, Germany) according to the manufacturer's protocol. Pyrosequencing primers were subsequently designed focusing on 3-5 targets CpG dinucleotides of TRDP, C16ORF89, ATAT1, and MSN. All primer sequences are depicted in
Supplementary Table 1. Each sample was analyzed in triplicate for this experiment. In brief, 20- $\mu$ laliquots of the PCR products were immobilized on streptavidin Sepharose HP beads (GE Healthcare, Little Chalfont, UK) and purified using a PyroMark Q24 vacuum workstation (Qiagen) according to the manufacturer's instructions. Then, the samples were denatured at $80^{\circ} \mathrm{C}$ for $2 \mathrm{~min}$ and annealed to a sequencing primer. Thereafter, the samples were subjected to analysis in a pyrosequencing machine. Nucleotide dispensation order and sequence analyses were performed with PyroMark Q24 software 2.0.6 (Qiagen). The pyrograms were analyzed in CpG assay mode to quantify the methylation percentage of each $\mathrm{CpG}$.

\section{Alu siRNA Transfection}

As previously described (Patchsung et al., 2018), Alu siRNA (sense, 5'-CUUUGGGAGGCCGAGGCGGGCGGAUCA-3'; antisense, 5'-AUCCGCCCGCCUCGGCCUCCCAAAGUG-3') was used to transfect the Tet+/Tet-treated AGO4sh knockdown cell lines. Cells were cultured with Tet (Tet+ or AGO4-) or without Tet (Tet- or AGO4+) for 7-9 days. One day before transfection, the treated and untreated cells were seeded into a 24 -well plate at $5 \times 10^{4}$ cells. Alu siRNA was then transfected to cells using Lipofectamine ${ }^{\circledR} 2000$ (Invitrogen) for $48 \mathrm{~h}$. The cells were collected to observe methylation changes by COBRA.

\section{LINE-1 or Alu-Combined Bisulfite Restriction Analysis}

To observe the methylation levels of LINE-1 or Alu in transfected cells, sodium bisulfite-treated DNA from each sample was amplified by using 1× PCR buffer (Qiagen), $0.2 \mathrm{mM}$ deoxynucleotide triphosphate (Biotechrabbit, Hennigsdorf, Germany), $1 \mathrm{mM}$ magnesium chloride (Qiagen), $25 \mathrm{U}$ of HotStarTaq DNA Polymerase (Qiagen), and $0.3 \mu \mathrm{M}$ of the LINE-1 met FW, RW or Alu met FW, RW primers, as shown in Supplementary Table 2. For LINE- 1 amplification, the cycling program was set at $95^{\circ} \mathrm{C}$ for $15 \mathrm{~min}$, followed by 30 cycles of $95^{\circ} \mathrm{C}$ for $45 \mathrm{~s}, 55^{\circ} \mathrm{C}$ for $45 \mathrm{~s}, 72^{\circ} \mathrm{C}$ for $45 \mathrm{~s}$, with a final extension $72^{\circ} \mathrm{C}$ for $7 \mathrm{~min}$. The LINE-1 PCR products were then subjected to COBRA by using $2 \mathrm{U}$ of TaqI (Thermo Scientific) with $0.5 \times$ TaqI buffer (Thermo Scientific) and incubated at $65^{\circ} \mathrm{C}$ overnight. For Alu amplification, the program was set as follows: $95^{\circ} \mathrm{C}$ for $15 \mathrm{~min}$ for one cycle and 40 cycles of $95^{\circ} \mathrm{C}$ for $45 \mathrm{~s}, 57^{\circ} \mathrm{C}$ for $45 \mathrm{~s}, 72^{\circ} \mathrm{C}$ for $45 \mathrm{~s}$, with a final extension $72^{\circ} \mathrm{C}$ for $7 \mathrm{~min}$. The Alu PCR products were subjected to COBRA using $2 \mathrm{U}$ of TaqI (Thermo Scientific), $2 \mathrm{U}$ of TasI (Thermo Scientific) with $5 \times$ nuclear extraction buffer 3 (New England Biolabs, MA, USA), and $1 \mu \mathrm{g} / \mu \mathrm{l}$ bovine serum albumin (New England Biolabs) and were incubated at $65^{\circ} \mathrm{C}$ overnight. Then, the cut PCR products were analyzed in $8 \%$ acrylamide gels with SYBR gel stain (Lonza, Basel, Switzerland). The band intensity of LINE-1 or Alu methylation was observed and measured by Strom 840 and ImageQuanNT software (Amersham Biosciences, Little Chalfont, UK) (Kitkumthorn and Mutirangura, 2011).

\section{Methylation Analysis}

For LINE-1 methylation analysis, the band intensities of LINE-1 products with sizes of $92,60,50,42$, and $32 \mathrm{bp}$ were applied for the 
calculation of LINE-1 methylation levels according to the following formula: $[(\mathrm{A}+2 \mathrm{C}+\mathrm{F}) \times 100] /(2 \mathrm{~A}+2 \mathrm{~B}+2 \mathrm{C}+2 \mathrm{~F})$, where $\mathrm{A}=$ band intensity at $92 \mathrm{bp} / 92, \mathrm{~B}=60 / 56, \mathrm{C}=50 / 48, \mathrm{D}=42 / 40, \mathrm{E}=32 / 28$, and $F=[(D+E)-(B+C)] / 2$. For Alu methylation analysis, the band intensities of five Alu products with sizes of 133, 90, 75, 58, and $43 \mathrm{bp}$ were used for the calculation of Alu methylation levels according to the following formula: $[(2 \mathrm{~F}+\mathrm{D}+\mathrm{C}) \times 100] /(2 \mathrm{~A}+$ $2 \mathrm{C}+2 \mathrm{D}+2 \mathrm{~F})$, where $\mathrm{A}=$ band intensity at $133 / 133, \mathrm{~B}=58 / 58$, $\mathrm{C}=75 / 75, \mathrm{D}=90 / 90, \mathrm{E}=43 / 43, \mathrm{~F}=[(\mathrm{E}+\mathrm{B})-(\mathrm{C}+\mathrm{D})] / 2$. The global methylation of LINE-1 or Alu measured in each replication was then used for statistical analysis using a paired-sample $T$-test.

\section{Argonaute 4 Plasmid Transfection}

Overexpression of AGO4 was performed by the using pIRESneoFLAG/HA AGO4 plasmid (Addgene, MA, USA). One day before transfection, HeLa cells were seeded at $2 \times 10^{5}$ cells $/ \mathrm{ml}$ in 6 -well plates in 2-ml DMEM containing 10\% FBS without antibiotics. The following day, plasmid transfection complexes were prepared; $2 \mu \mathrm{g}$ of the AGO4 plasmid and the pcDNA3.1/myc-HIS A empty plasmid (PC) (Invitrogen) were transfected into HeLa cells with $10 \mu$ of Lipofectamine ${ }^{\circledR} 2000$ (Invitrogen) mixed with Opti-MEM ${ }^{\circledR}$ reduced serum media (Invitrogen) in a total volume of $500 \mu \mathrm{l}$ according to the manufacturer's protocol. The transfection duration was $72 \mathrm{~h}$ for the observation and quantification of LINE-1 or Alu methylation; overexpression of AGO4 mRNA was also confirmed.

\section{RNA Preparation and cDNA Synthesis}

Cells were harvested using trypsinization and washed with phosphate-buffered saline, after which Trizol ${ }^{\mathrm{TM}}$ (Invitrogen) was added to the cell pellet according to the manufacturer's protocol. Then, 500-1,000 ng of total RNA from each sample was used to synthesize cDNA using the RevertAid ${ }^{\mathrm{TM}}$ first-strand cDNA synthesis kit (Thermo Scientific) according to the manufacturer's specification.

\section{Real-Time PCR}

To observe AGO4 mRNA expression and to quantify, AGO4bound LINE-1 or Alu DNA levels, real-time PCR was carried out using Power SYBR ${ }^{\circledR}$ Green PCR master mix (Applied Biosystems, CA, USA) with AGO4 FW, RW (GAPDH FW, RW was used as an internal control); copy LINE-1 FW, RW; or copy Alu FW, RW (shown in Supplementary Table 2). The amplifications were performed within a 7,500-fast real-time PCR system (Applied Biosystems). The $\Delta \Delta \mathrm{CT}$ method (Livak and Schmittgen, 2001) was used to calculate the amount of AGO4-bound LINE-1 or Alu in AGO4 plasmid overexpressing cells compared with pcDNA3.1 empty plasmid-transfected cells. Paired sample T-tests were performed for statistical analysis at CIs of $95 \%$.

\section{Cell-Penetrating Peptide Argonaute 4 Plasmid Construction and Protein Production}

To produce cell-penetrating peptide AGO4 (CPP-AGO4) and $\mathrm{CPP}$ - enhanced green fluorescent protein recombinant proteins, 9× arginines (R9) as CPP and AGO4 mRNA (NM_017629.3) were in-frame inserted into the pRSET A vector (Thermo
Scientific) between BamHI and EcoRI sites. Both vectors were constructed by the GeneArt ${ }^{\mathrm{TM}}$ Plasmid Construction Service (Thermo Scientific). The fidelities of the sequences were confirmed by Sanger sequencing.

The CPP-AGO4 vector was transformed into BL21(DE3)pLysS competent cells (Promega, WI, USA) for CPP-AGO4 protein production. The cells were then cultured in 2YT medium, and overexpression was induced by $1 \mathrm{mM}$ isopropyl-1-thio- $\beta-\mathrm{D}$ galactopyranoside (Sigma-Aldrich) until the OD600 reached 0.8 . The cells were cultured further for $20 \mathrm{~h}$ at $20^{\circ} \mathrm{C}$ in a $250-\mathrm{rpm}$ incubation shaker. Then, the cells were collected by centrifugation at $10,000 \mathrm{rpm}$ for $15 \mathrm{~min}$ at $10^{\circ} \mathrm{C}$. Cell pastes were lysed by lysis buffer [50 mM Tris- $\mathrm{HCl}$ (pH 8.0), $300 \mathrm{mM} \mathrm{NaCl}, 10 \mathrm{mM}$ imidazole, 10\% glycerol, $10 \mathrm{mg} / \mathrm{ml}$ lysozyme, $1 \%$ Triton $\mathrm{X}-100$, and $1 \times$ protease inhibitor] and sonicated and centrifuged at $10,000 \mathrm{rpm}$ at $10^{\circ} \mathrm{C}$ for $20 \mathrm{~min}$ to harvest the crude protein supernatant. CPP-AGO4, which was soluble in supernatant, was purified on a HisTrap ${ }^{\text {TM }}$ HP (GE Healthcare) column according to the manufacturer's instructions. Purified CPP-AGO4 protein was confirmed using Coomassie ${ }^{\circledR}$-Brilliant-Blue-R-250 (C.I.42660) (Merck Millipore)stained 6\% SDS polyacrylamide gel electrophoresis. Furthermore, Western blot analysis was performed using 1:2500 AGO4 (D10F10) (Cell Signaling), 1:5,000 anti-rabbit IgG, HRP-linked [\#7074] (Cell Signaling) or 1:2,500 anti-6X HIS tag ${ }^{\circledR}$ [HIS.H8] (ab18184) (Abcam), and 1:5,000 anti-mouse IgG, HRP-linked [\#7076] (Cell Signaling) antibody. Concentrations of both purified proteins were determined by Pierce BCA protein assay kit (Thermo Scientific).

\section{Cell-Penetrating Peptide Argonaute 4-Alu Transfection}

The purified CPP-AGO4 was conjugated to sgRNA of Alu (5'-AUCCGCCCGCCUCGG CCUCCCAAAG-3') using a slicing assay as previously described (De and MacRae, 2011) with some modifications. Briefly, $10 \mu \mathrm{g}$ of CPP-AGO4 protein was mixed with $200 \mathrm{nM}$ of sgRNA in conjugation buffer [ $1.5 \mathrm{mM}$ $\mathrm{MgCl}_{2}, 5 \%$ glycerol, $50 \mathrm{mM} \mathrm{KCl}$, and $20 \mathrm{mM}$ Tris- $\mathrm{HCl}(\mathrm{pH}$ 7.0)] and incubated in a $37^{\circ} \mathrm{C}$ water bath for $30 \mathrm{~min}$. Then, the conjugated complexes of CPP-AGO4-sgRNA were dropped into $500 \mu \mathrm{l}$ DMEM-cultured $7.5 \times 10^{4}$ cells in a 24 -well plate to allow the complexes to be internalized into the cells and induce methylation at specific targets homologous to the sgRNA; noninduced CPP-AGO4 represented as buffer was used as a control. After transfection for $72 \mathrm{~h}$, cells were collected to measure changes of methylation levels of target genes.

\section{RESULTS}

\section{Argonaute 4 is Related to Promoter Methylation}

To determine whether any AGO protein is associated with DNA methylation, we first performed whole-genome comparisons between the promoter methylation dataset (GSE20598) and AGO-binding sites (CLIPZ database) (Komashko and Farnham, 2010; Khorshid et al., 2010). The GSE20598 dataset provided the amount of DNA methylation in HEK293 cells; the CLIPZ 
database provided AGO-binding locations in the same cells. On the basis of these two datasets, the association between DNA methylation and AGO proteins was identified. Among all AGO proteins, AGO4 showed the strongest correlation with DNA methylation, as summarized from multiple probes (Pearson correlation coefficient $=0.17$ and $p$-value $=1.48 \times 10^{-3}$ ) (Figures 1A-D).

The increase in the number of AGO4-binding sites in a promoter is proportional to the amount of methylation at the promoter. Moreover, the binding position of AGO4 is correlated with the methylation of a single probe (Figure 1E). Sequence logos and positions are reported in relation to the transcriptional start sites (TSS) of AGO4 binding and methylation (Supplementary Figure S1). Interestingly, AGO4 binds to the sense strand of methylated DNA located immediately downstream of the TSS (Supplementary Figure S2).

Moreover, we found that DNA methylation is associated with AGO-binding sites (Figures 2A, B). The highly methylated probes are in proximity with the binding sites of AGO1, AGO2, AGO3, and AGO4 proteins. This is indicated by odds ratio (OR) and $95 \%$ confidence interval $(\mathrm{CI})>1$. In contrast, the number of association studies of the control protein, PUMILIO2, shows $\mathrm{OR}$ and $\mathrm{CI}<1$. In Figure 2A, it demonstrated $\mathrm{OR}$ and $\mathrm{CI}$ when the ChIP sequences that are perfectly matched with the human genome were counted, whereas Figure 2B reported approximate match. Other similar sequences contain mismatch, insertion, and deletion being alternative targets. All four AGOs (AGO1, AGO2, AGO3, and AGO4) showed OR and CI >1 in several tests. However, AGO4 showed the higher OR and the lowest $p$-value in most tests (Figure 2 and Supplementary Table 3). By allowing approximate match, AGO4 shows the highest $\mathrm{OR}$ at binding length $\geq 15 \mathrm{bp}, \mathrm{OR}=4.09,95 \% \mathrm{CI}=3.73$ to 4.50 , $p$-value $=1.48 \mathrm{E}$ 214 (Figure 2B and Supplementary Table 3).

\section{The Argonaute 4 Protein is Involved in De Novo Methylation of Argonaute 4-Binding Genes}

To investigate AGO4-binding genes and the role of AGO4 in DNA methylation, we obtained target genes from analyses of

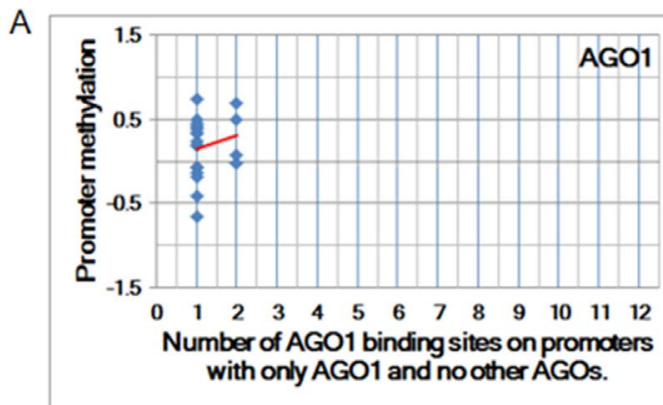

C

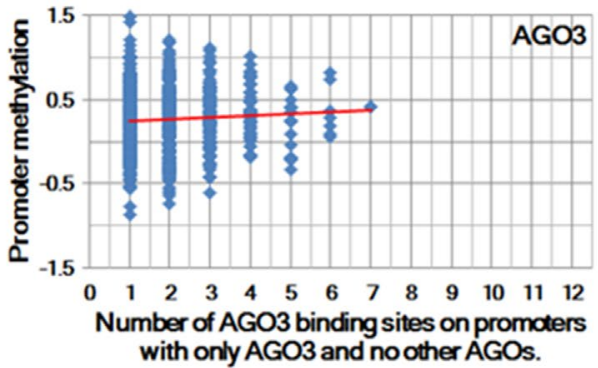

B

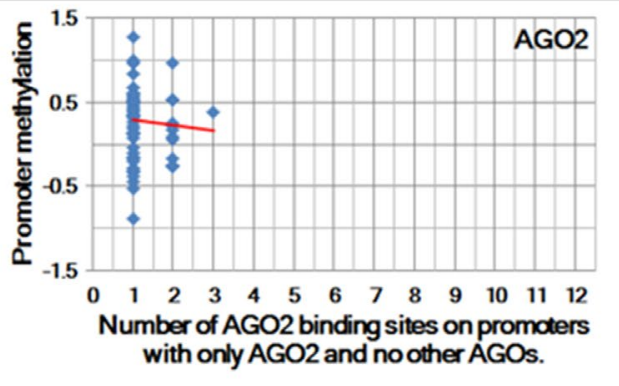

D

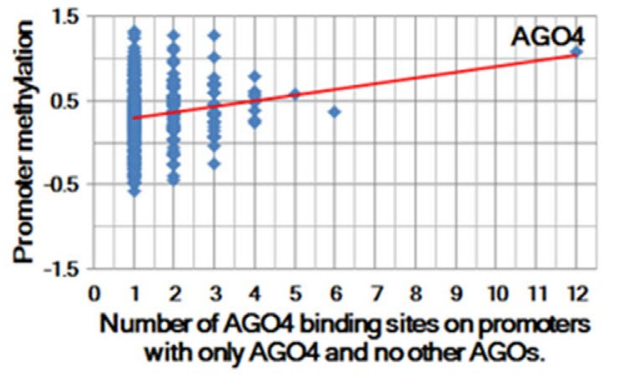

$\mathrm{E}$

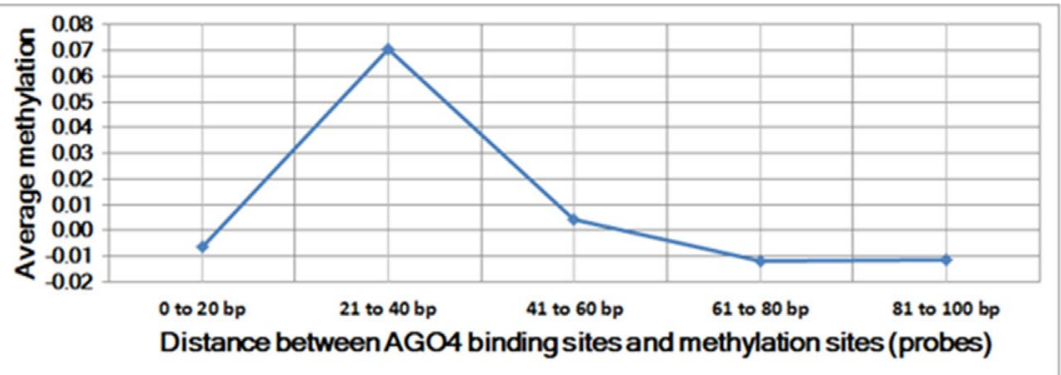

FIGURE 1 | The correlation between Argonaute (AGO) proteins and promoter methylation. (A to $\mathbf{D}$ ) Promoter methylation vs. the number of AGO-binding sites. The Pearson correlation coefficients for $A$ to $D$ are $0.01,-0.06,0.06$, and 0.17 , and the corresponding $p$-values are 8.63E-01, 6.51E-01, 1.11E-01, and 1.48E-03, respectively. (E) Average methylation vs. proximity to AGO-binding sites. Each column represents the average amount of methylation at a single probe if the proximity is within a predefined distance. 


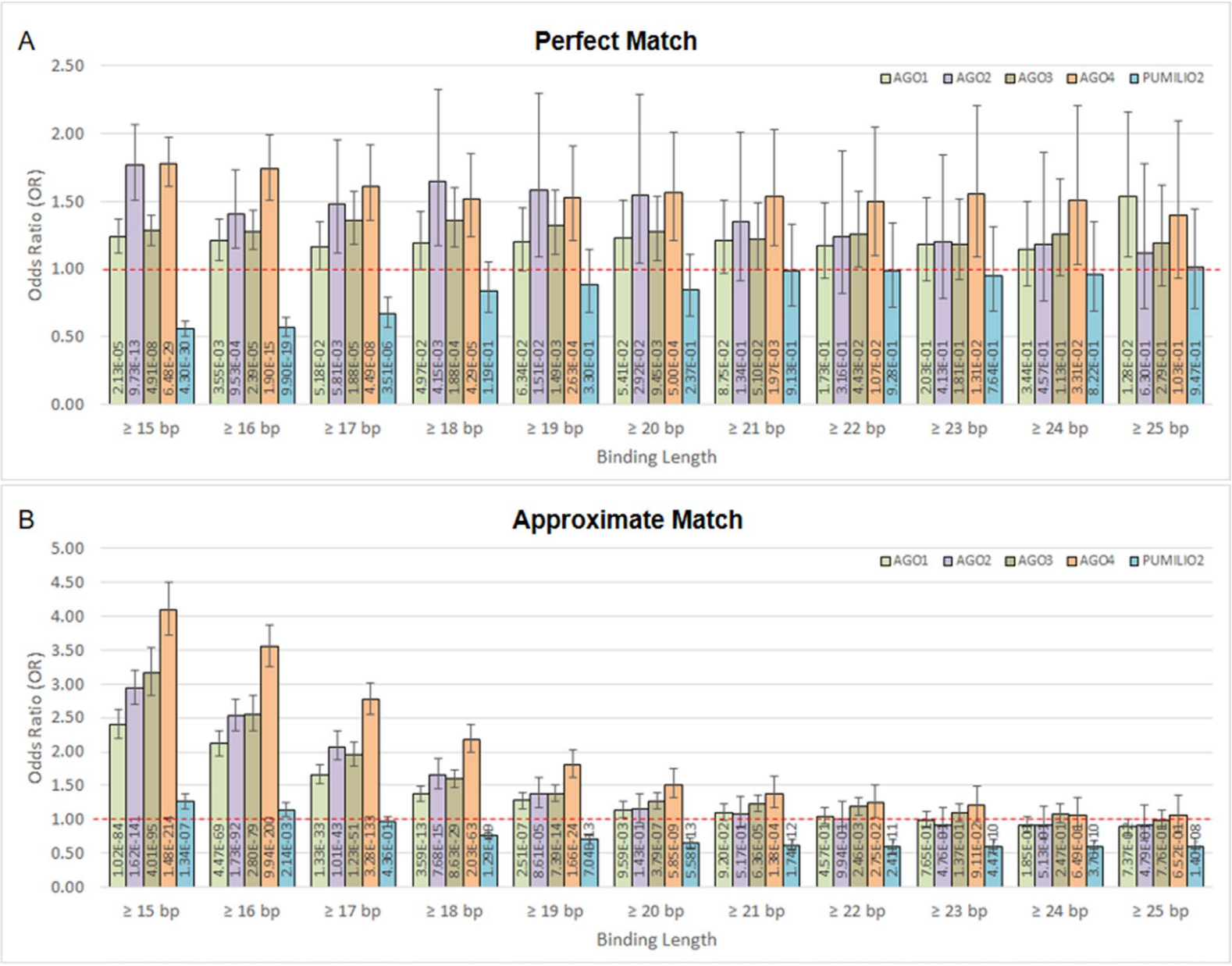

FIGURE 2 | The association between methylation levels and protein-binding sites. The Chi-square $p$-values are calculated from $2 \times 2$ contingency tables that count the number of methylation probes. The rows of a contingency table separate highly and lowly methylated probes, whereas the columns separate probes that are in proximity with protein-binding sites and probes that are not. Note that a single probe might be in proximity with multiple protein. (A) Only ChIP DNAs that are perfectly matched with the human genome are included. (B) Only ChIP DNAs that are approximately matched with the human genome are included. This also includes perfectly matched DNAs.

the GSE20598 and CLIPZ databases. These bioinformatics data provided us with a large number of genes that show a connection between AGO4-binding and promoter methylation. We randomly selected eight loci of three genes: TRDP, C16ORF89, and ATAT1 that have high level of DNA methylation and AGO4 binding to study the interaction between AGO4 and DNA methylation. MSN, which lacks AGO4 binding, was used as a negative control. The experiments were carried out by depleting endogenous AGO4 using a tetracycline-regulated shRNA-expression system in the HEK293 cell line (AGO4sh). The timing of tetracycline (Tet) and 5-AC treatment is shown (Figure 3A). Depletion of AGO4 mRNA expression was confirmed (Figure 3B). After the cells were cultured with Tet (Tet+) or without Tet (Tet-) for 7 days, they were collected to confirm the AGO4-binding genes. All four selected genes bound large quantities of AGO4; C16ORF89 is provided as an example (Figure 3C); the other genes showed similar results (Supplementary Figures S3A, B), with the exception of MSN
(Figure 3D). Methylation levels were also evaluated; however, there was no significant difference in methylation levels between the Tet+ and Tet- cells at all nine loci of the four known AGO4binding genes or MSN (Figures 3E, F and Supplementary Figures S4A-G at Tet- and Tet+ bars). Thereafter, the HEK293 cell line was treated with a combination of Tet and 5-AC to limit AGO4 mRNA and inactivate DNA methyltransferase activity for two additional days, until day 9; methylation changes were then investigated. From days 7 to 9 , the methylation levels of all loci were significantly reduced in Tet+ and 5-AC+ shAGO4induced cells compared with Tet- and 5-AC+ cells (Figures 3E, F and Supplementary Figures S4A-G at Tet- 5-AC+ and Tet+ $5-\mathrm{AC}+$ bars). This finding suggested a role of AGO4 in the demethylation of AGO4-bound sequences.

The mechanism by which AGO4 prevented demethylation by 5-AC suggested a role of AGO4 in de novo DNA methylation. To observe the de novo methylation function of endogenous AGO4, cells were cultured continuously with Tet and 5-AC for 9 days. 

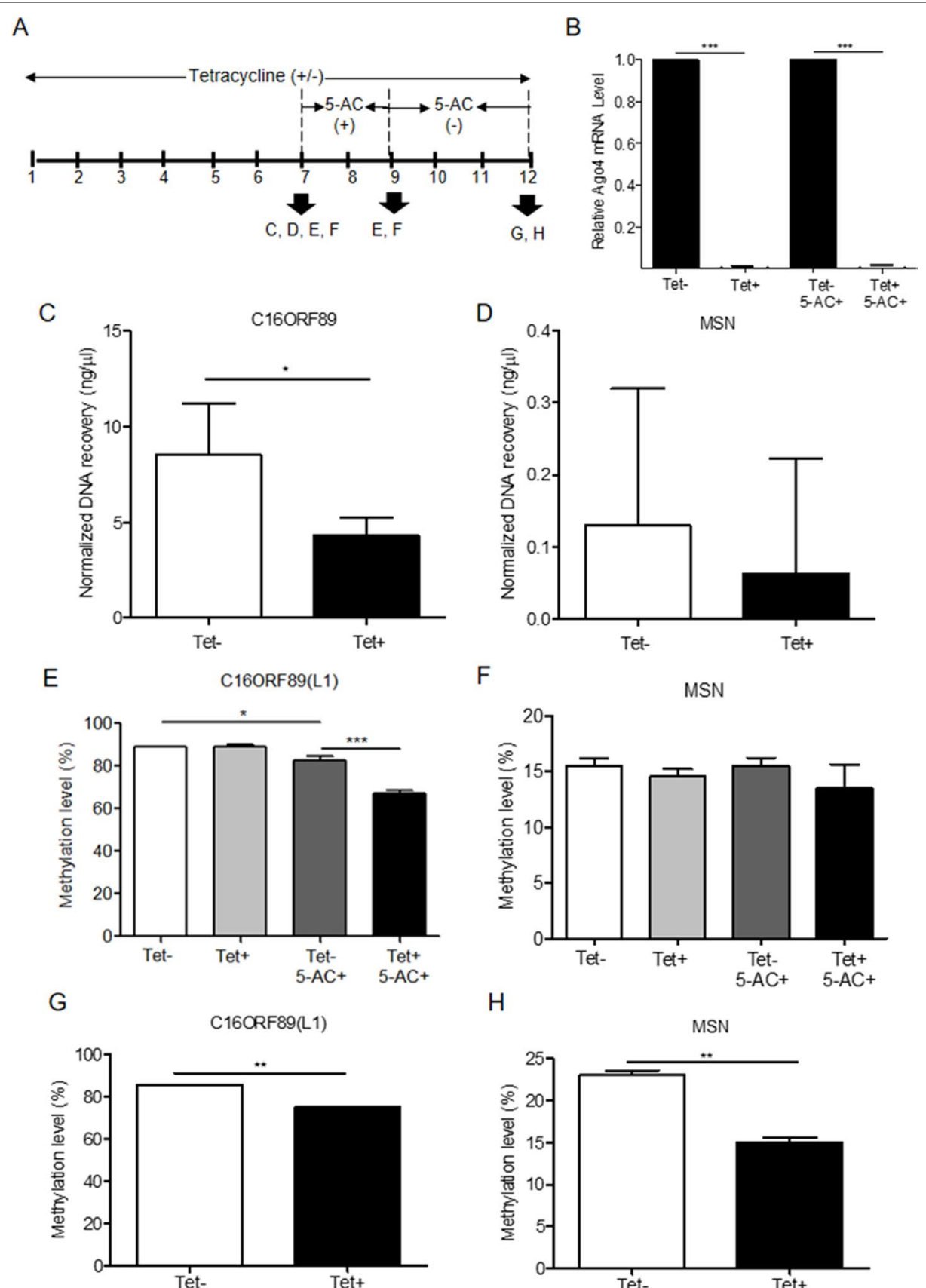

$\mathrm{H}$
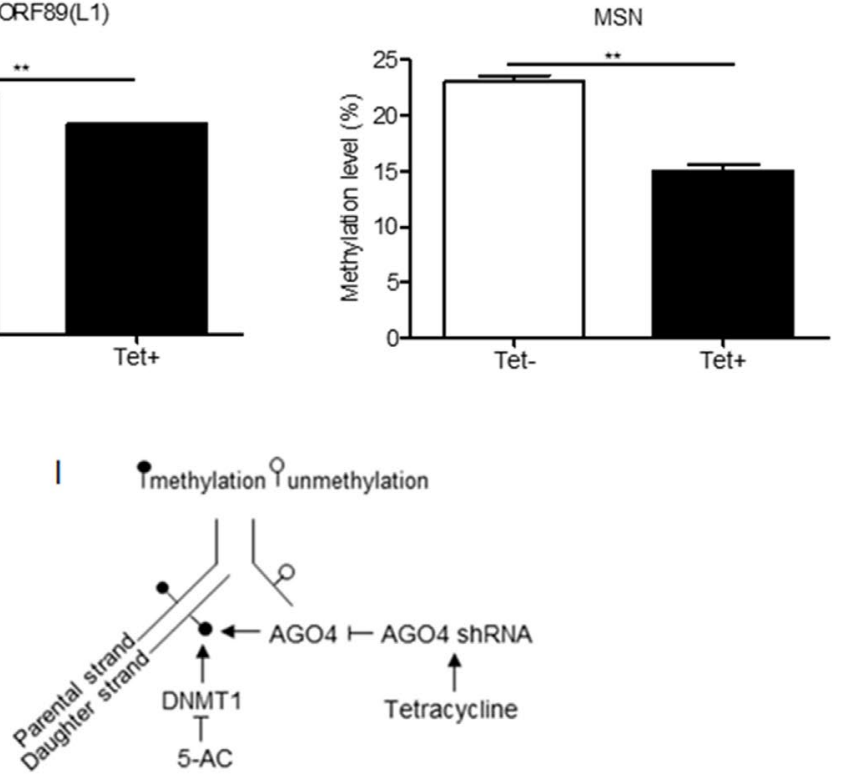

FIGURE 3 | Continued 


\begin{abstract}
FIGURE 3 | Association of the AGO4-binding genes and methylation levels. (A) Scheme showing that tetracycline-treated cells switch off AGO4 protein expression (Tet+) from day 1 to 12 and that 5'-azacytidine treatment from day 7 to 9 inhibits DNA methyltransferase (5-AC). (B) Detection of AGO4 mRNA in Tet- (AGO4 expression) and Tet+ (No AGO4 expression) cells; AGO4 was significantly expressed in the absence of Tet. (C) Confirmation of AGO4-binding genes showed that AGO4 only bounds to the selected gene from bioinformatics data as exemplified by C16ORF89. (D) However, AGO4 did not bind to a gene lacking the AGO4binding site, MSN. (E) The AGO4 methylation level of the gene, which contains AGO4-binding sites, was increased due to the presence of the AGO4 protein (Tet-). This increased methylation level was not associated with the presence of DNA methyltransferase (5-AC+). (F) These results were not observed for a gene lacking AGO4-binding sites, MSN. (G to H) Recovery of DNA methylation levels is found in cells expressing the AGO4 protein (Tet-) with 5'-azacytidine withdrawal in both of AGO4-binding gene, C16ORF89 and non-AGO4-binding gene, MSN; AGO4 is inferred to methylate previously demethylated loci. The above data are the representative dataset from three independent experiments presented as the mean \pm SEM. Statistical analyses were performed using a paired-sample $t$-test, where $p<0.05, p<0.01$, and $p<0.005$ are represented as ${ }^{*},{ }^{\star *}$, and ${ }^{\star \star \star}$, respectively, where Tet+ means tetracycline treatment, 5 -AC+ means azacytidine treatment, and Tet- and 5-AC- mean untreated groups (I). Schematic overview of the role of AGO4 in de novo methylation. After DNA replication, DNA methylation is maintained by DNMT1 by the recognition of hemimethylated CpG on the parental strand as a template and the addition of newly methylated CpG to the daughter strand. DNMT1 is inhibited by the action of 5-AC, and the methylation level should be decreased by half under 5-AC treatment. In our study, when tetracycline was added, AGO4 shRNA was manipulated, resulting in AGO4 expression repression. Thus, without tetracycline, AGO4 is upregulated and binds to DNA loci, and DNA methylation is maintained, although 5-AC is added, suggesting that AGO4 involved in de novo methylation
\end{abstract}

Then, the cells were cultured for 3 days (days 9 to 12) without 5 -AC and with or without Tet. The methylation levels of all loci were recovered in cells lacking tetracycline treatment (Tet-, 5-AC+) (Figures 3G, H and Supplementary Figures S5A-G). Moreover, tetracycline and scramble shRNA by themselves did not influence DNA methylation levels significantly (Supplementary Figure S6). This finding means that AGO4 reintroduces DNA methylation to previously demethylated loci, as shown in Figure 3I.

\section{Argonaute 4 as a Master Protein Regulates Human RNA-Dependent DNA Methylation}

Previously, we demonstrated that Alu element siRNA (Alu siRNA) transfection increased Alu methylation (Patchsung et al., 2018). To determine whether siRNA can promote methylation in human cells and whether this process is dependent on AGO4, Alu siRNA was used to transfect the AGO4sh-induced HEK293 cell line, and the cells were cultured under Tet+ or Tet- conditions. We found that Alu siRNA increased the Alu methylation level when AGO4 was not limited; on the other hand, Alu siRNA did not promote methylation when AGO4 was depleted in Tet+-cultured HEK293 cells (Figure 4). Therefore, Alu siRNA may form an RdDM complex with AGO4 to methylate ALU sequences.

To determine whether human AGO4 is a main protein in the RdDM complex and directly methylates DNA, we transfected a hemagglutinin (HA)-tagged AGO4 plasmid into HeLa cells and evaluated whether the HA-AGO4 protein could methylate DNA. We also used an empty plasmid (pcDNA, or PC more briefly) as a control plasmid. Overexpression of AGO4 after transfection was detected after $72 \mathrm{~h}$ at the mRNA level and at 24, 36, 48, and $72 \mathrm{~h}$ at the protein level (Figures 5A, B and Supplementary Figure S7). At $72 \mathrm{~h}$ post-transfection, the genome-wide interspersed repetitive sequence methylation of both LINE-1 and Alu was observed (Figure 5C). Then, AGO4 localization was observed using an HA antibody in a ChIP experiment. We discovered that AGO4-HA preferentially bound to LINE-1 and Alu sequences (Figure 6A), which were highly methylated (Figure 6B).

To date, the technology of using cell-penetrating peptides (CPP) is developed to deliver biological cargoes to target cells
(Madani et al., 2011) and to apply as therapeutic molecules for clinical application (Copolovici et al., 2014). By this advancement, we constructed arginine-rich CPP-tagged AGO4 and conjugated it with Alu sgRNA. The complex was transfected to cells, aimed to promote Alu methylation. We found that the result was consistent when CPP-AGO4-Alu was transfected to HeLa cells; Alu methylation was augmented significantly in CPP-AGO4-Alu-transfected cells but not in their control counterparts (Figure 7A). LINE-1 methylation level was studied to evaluate off targets, and we found that LINE-1 methylation level was not increased by CPP-AGO4-Alu-transfected cells (Figure 7B). Therefore, HA-AGO4 de novo methylates LINE-1 and Alu sequences, as well as CPP-AGO4-Alu can promote Alu methylation with no off-target effects.

\section{DISCUSSION}

In this study, we performed several experiments to determine that human AGO4 is a crucial protein in the RdDM complex. First, we found AGO protein locational overlap with DNA methylation. Second, the combination of AGO4 downregulation and 5-AC treatment can demethylate AGO4-bound loci. Third, AGO4 expression is required for Alu methylation upon Alu siRNA transfection. Finally, AGO4 overexpression and AGO4 protein transfection increase DNA methylation of AGO4bound sequences.

Referring to our bioinformatics study, we used Pearson correlation coefficients and the $2 \times 2$ contingency tables to evaluate the correlation of promoter methylation and the number of AGO-binding sites. We found that both of these statistical tools did not provide much significant difference between each human AGO. Even a low-positive correlation and a large deviation were found. Nevertheless, AGO4 showed the most significant p-values and the highest OR. Therefore, we hypothesized that human AGO4 plays a role in RdDM. Our study showed that AGO1-AGO3 are also statistically significant, however, with lesser degree than AGO4 (Figure 2A, B). The RdDM function of human AGO4 might be redundant with other AGOs. This may explain why AGO4 double knockout mice are viable except for detection in male fertility (Modzelewski et al., 2012). 


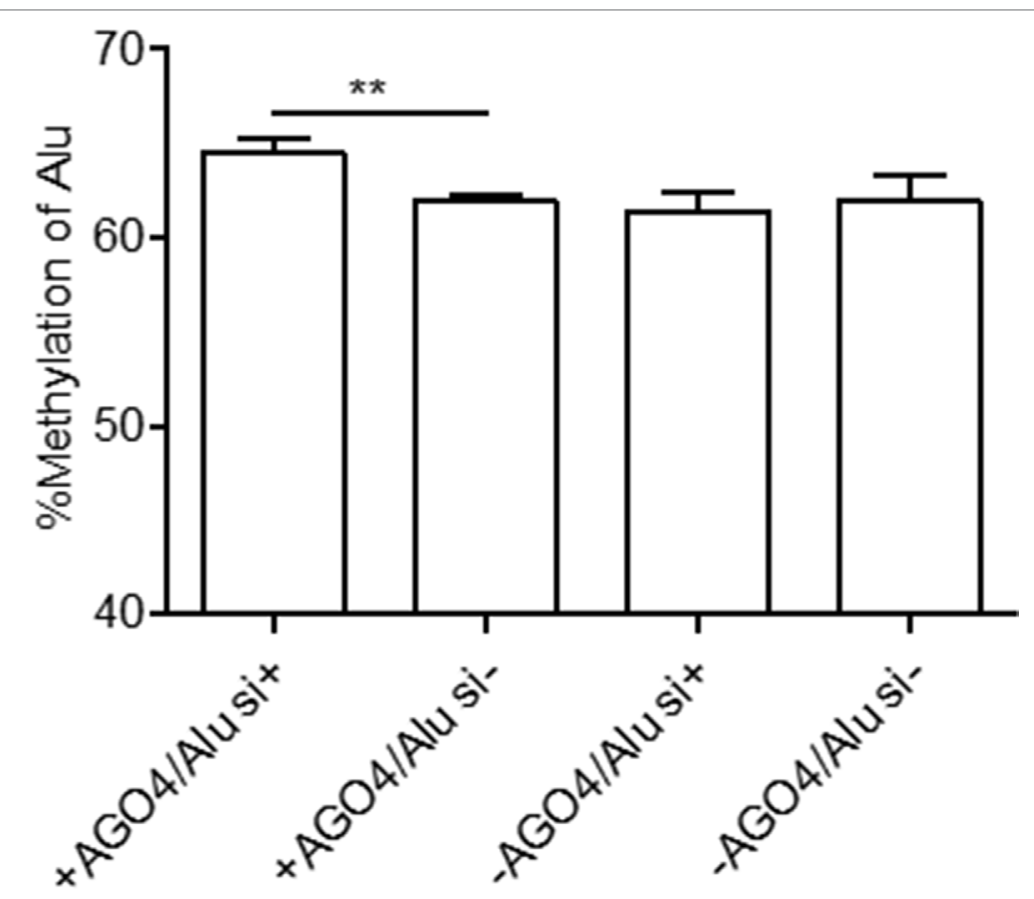

FIGURE 4 | Alu methylation upon Alu siRNA transfection in Tet-controlled AGO4-expressing cells. The Alu methylation level was significantly increased when AGO4 was upregulated under Alu siRNA transfection. The above data are the representative dataset from six independent experiments presented as the mean \pm SEM. Statistical analysis was performed using an unpaired $t$-test where $p<0.01$ is represented as **
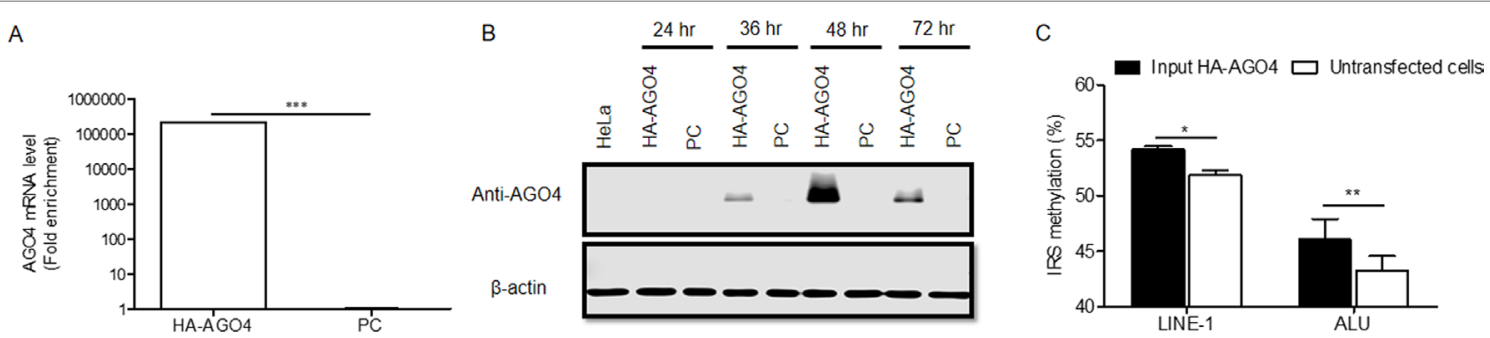

FIGURE 5 | Overexpression of HA-AGO4 increases global genomic methylation. (A) Confirmation of AGO4 mRNA expression in AGO4- or PC-overexpressing cells after transfection for $72 \mathrm{~h}$ by using real-time PCR showed that AGO4 mRNA was significantly upregulated in AGO4-overexpressing cells, and (B) Western blot analysis showed the expression of the $\mathrm{HA}$-AGO4 protein in a time-course experiment. $\beta$-Actin was used to confirm equal protein loading of each lane. AGO4 protein expression was at the highest level at $48 \mathrm{~h}$ after transfection. (C) Overexpression of HA-AGO4 resulted in a significant increase in interspersed repetitive sequence methylation in the input (cell lysate) HA-AGO4 compared with untransfected HeLa cells, detected at $72 \mathrm{~h}$ post-transfection. The above data in A and $\mathrm{C}$ are the representative dataset from five independent experiments presented as the mean \pm SEM. Statistical analyses were performed using a paired $t$-test where $p<0.05$, $p<0.01$, and $p<0.005$ are represented as ${ }^{*},{ }^{* \star}$, and ${ }^{\star \star \star}$, respectively.
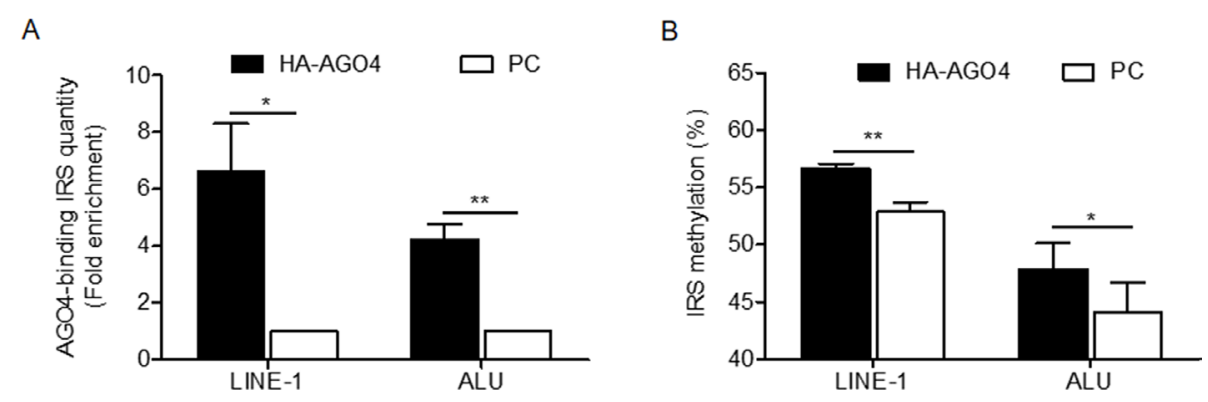

FIGURE 6 | AGO4 localization is involved in RdDM by introducing genomic DNA methylation in human cells. (A) ChIP experiments using a hemagglutinin (HA) antibody showed elevation of the levels of AGO4-binding LINE-1 or ALU found in AGO4-overexpressing cells compared with their control counterparts.

(B) Moreover, the binding of the AGO4 protein to interspersed repetitive sequence increased DNA methylation. 


\section{A}

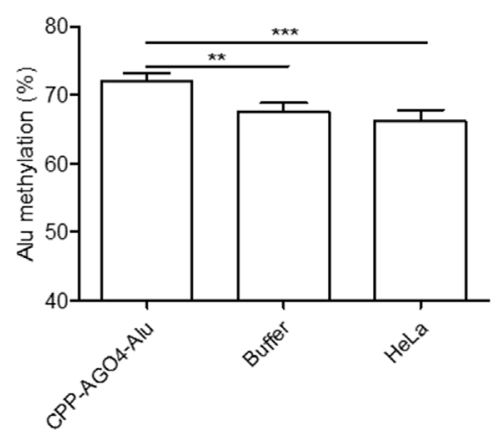

B

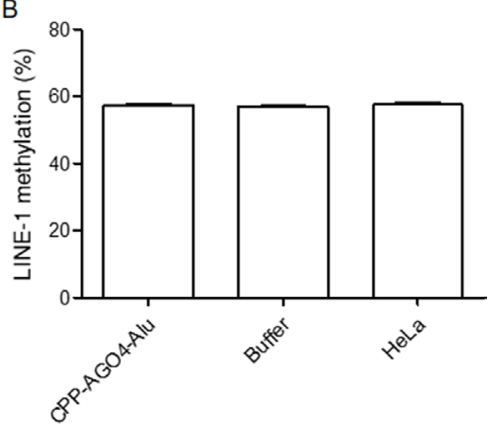

FIGURE 7 | AGO4 protein specifically induced DNA methylation of target loci. By using CPP-AGO4 conjugated with Alu sgRNA (CPP-AGO4-Alu) transfected to HeLa cells, we found that (A) Alu methylation level was significantly increased in CPP-AGO4-Alu transfected cells, while Alu methylation was not promoted in control counterpart groups. (B) While LINE-1 methylation level was not changed, this means the complex has no off targets to LINE-1. The representative dataset was obtained from five independent experiments. Statistical analyses were performed using a paired-sample $T$-test where $p<0.05$ and $p<0.01$ are represented as * and **, respectively, where buffer means non-inducible CPP-AGO4 transfection.

Neither AGO4 downregulation nor 5-AC treatment alone could effectively demethylate AGO4-bound loci. These findings suggested that AGO4 downregulation and 5-AC treatment demethylated DNA by different mechanisms. 5-AC functions as a DNA-hypomethylating agent by inhibiting human DNA methyltransferase 1 (DNMT1). DNMT1 plays a role in the maintenance of DNA methylation by recognition of hemimethylated $\mathrm{CpG}$ and replication of $\mathrm{CpG}$ methylation to the opposite DNA strand (Stresemann and Lyko, 2008). Thus, 5-AC treatment should cause the level of DNA methylation to decrease after each round of DNA replication. In the present study, it was found that 5-AC could not reduce the methylation level when AGO4 was not downregulated. Therefore, AGO4 may play a role in de novo methylation and is not exclusively involved in DNA methylation maintenance, being inhibited by 5-AC (Figure 3I). Moreover, here, we demonstrated that newly synthesized AGO4 proteins methylated new loci. First, upregulated exogenous AGO4 increased Alu and LINE-1 methylation. Second, the AGO4 proteins, synthesized after stopping AGO4 shRNA induction, increased $M S N$ methylation. We postulated that recently translated AGO4 proteins may bind to free small RNA that normally did not load onto AGO4. As demonstrated by Figure 2B, the binding of AGO4 did not require the perfect match; for that reason, this increased the possibility for newly forming AGO4 loading small RNA complex to methylate new loci.

In addition to confirming whether AGO4 is involved in RdDM, Alu siRNA transfection was performed. The increase in Alu methylation was significant only when AGO4 was present, verifying that AGO4 forms an RdDM complex together with siRNA. Moreover, overexpression of exogenous AGO4 also resulted in apparently higher methylation levels of LINE-1 and Alu, including CPP-AGO4-Alu transfection that can specifically promote Alu methylation; this finding is understandable because LINE-1 and Alu contribute a large number of endogenous siRNAs (Hadjiargyrou and Delihas, 2013).

Human RdDM complexes should be further explored in detail. In plants, there are two effector AGO proteins that are involved in RdDM, one of which is AGO4 (Matranga et al., 2005). AGO4/ siRNA complexes are selectively transported into the nucleus and then recruit de novo methylase DRM2 to methylate target DNA (Ketting, 2011; Hegge et al., 2018). As noted before, DRM2 plays a role in plant RdDM and is an ortholog of human DNMT3, which is in accordance with the results we obtained showing that AGO4 participates in de novo methylation. Therefore, the association of RdDM effector protein complexes, including AGO4, each DNMT (DNMT3A/3B, and DNMT1), and other proteins that serve as transcription factors should be investigated. Another issue that might be a piece of the puzzle is that plant RdDM is processed by RNA polymerase IV and V (Pol IV and Pol V). These enzymes have conserved amino acid sequences similar to Pol II, but their largest domain is different from Pol II, suggesting that this domain might have evolved to function in RdDM (Huang et al., 2009). However, Pol I, II, and III are present in humans (Vannini and Cramer, 2012), and the specialized function of Pol involved in $\mathrm{RdDM}$ should therefore be identified. Moreover, evidence from Schizosaccharomyces pombe and human cells showed the presence of AGO1-mediated heterochromatin formation during transcriptional gene silencing, together with small RNAs (Kim et al., 2006; Qi et al., 2006); similarly, AGO3 is loaded by PIWIinteracting RNAs derived from transposon mRNAs in Drosophila leading to the hypothesis that AGO3-generating PIWI-interacting RNAs could play a role in chromatin formation at transposon loci (Ye et al., 2012). Thus, it is possible that human AGO1 and AGO3 could have interrelated effects on the methylation levels of histones and DNA. All of these observations give rise to one last question that should be addressed: is there any interplay between DNA methylation and chromatin modification caused by cohesion of AGO proteins? Notably, our genome-wide correlation study showed that the correlation between AGO2 and methylation was far less significant than that of the other AGO protein; thus, AGO2 may not play a role in RdDM and may only function in RNAi processes only. Furthermore, a study in mice indicated by generating individual AGO-deficient cells, each AGO possesses miRNA silencing activity. However, AGO2 yielded the greatest effect (Su et al., 2009). Consistent with the results of PR-9 antigene transfection in AGO-depleted cells, AGO2-lacking cells showed the largest decrease in PR-9 gene expression, while other AGOs had little effect (Chu et al., 2010). As the greatest quantity 
of AGO2 was found in humans, all of these lines of evidence led us to address whether the amount of AGO protein in cells could be a factor determining the pathway being used for gene silencing.

DNA methylation plays roles in several processes, such as genomic imprinting, $\mathrm{X}$-inactivation, cell differentiation, aging, and adaptation to the environment. Our genome-wide study of colocalization between AGO4 binding and DNA methylation revealed that human AGO4 methylates DNA located immediately downstream of the TSS (Supplementary Figure 2). This location was also identified in our previous tissue-specific DNA methylation study (Muangsub et al., 2014), suggesting that the tissue specificity might be modulated by RdDM. However, as AGO4 can also bind both LINEs and SINEs and contribute to the control of gene expression and prevention of genomic instability (Mutirangura, 2019), other functions of AGO4 should also be explored.

Moreover, AGO has been proposed as a genomic editing tool in prokaryotes (Hegge et al., 2018). To date ZFNs, TALENs, CRISPRcas9, and DNMT3A with a catalytically inactive Cas9 have been developed for future personalized medicine at both the genomic and epigenomic levels (Gaj et al., 2013; Liu et al., 2016; Vojta et al., 2016). Epigenomic editing could be beneficial in ex vivo or in vitro therapy. Therefore, CPP-AGO4, which is a human protein, might pave the way to be used as a new platform of therapies using protein transduction technology in the future. By this technology, it can avoid some drawbacks of using transgene technology, for instance, an insertion of recombinant DNA into host genomes that might lead to unwanted mutations (Bachu et al., 2015).

In summary, human AGO4 plays a role in siRNA-mediated DNA methylation, implying that RdDM exists in humans and is involved in de novo methylation. Further studies are needed to observe the roles of RdDM in human cells, and this study might shed light on the use of human $\mathrm{AGO} 4$ for future applications in epigenomic therapy.

\section{DATA AVAILABILITY STATEMENT}

All datasets generated for this study are included in the manuscript and the supplementary files.

\section{AUTHOR CONTRIBUTIONS}

KC performed all experiments related to AGO4 transfection and and wrote the manuscript. PP performed all Tet-on related experiments and wrote this part of the manuscript. CA performed all of the bioinformatics analyses and wrote this part

\section{REFERENCES}

Adhikari, S., and Curtis, P. D. (2016). DNA methyltransferases and epigenetic regulation in bacteria. FEMS Microbiol. Rev. 40 (5), 575-591. doi: 10.1093/femsre/fuw023

Anwar, S., Wulaningsih, W., and Lehmann, U. (2017). Transposable elements in human cancer: causes and consequences of deregulation. Int. J. Mol. Sci. 18 (5), 974. doi: 10.3390/ijms18050974

Bachu, R., Bergareche, I., and Chasin, L. A. (2015). CRISPR-Cas targeted plasmid integration into mammalian cells via non-homologous end joining. Biotechnol. Bioeng. 112 (10), 2154-2162. doi: 10.1002/bit.25629 of the manuscript. MP performed Alu siRNA experiment. PI and NI prepared Tet-on cells. AM conceived and designed the study, analyzed the data, and wrote and edited the manuscript.

\section{FUNDING}

This work was supported by the Thailand Research Fund [DPG5980005, RSA5980060]; a 2019 Research Chair Grant from the National Science and Technology Development Agency, Thailand; the Anantara Siam Bangkok Hotel, Four Seasons Hotel Care for Cancer Fun Run in coordination with the Thai Red Cross Society; the Chulalongkorn University $100^{\text {th }}$ Year Birthday Anniversary Doctoral Degree Scholarship; the Chulalongkorn Academic Advancement in Its $2{ }^{\text {nd }}$ Century Project; and the Thailand Research Fund through the Royal Golden Jubilee Ph.D. Program [PHD/0131/2554 to MP (student) and Professor AM (advisor)].

\section{SUPPLEMENTARY MATERIAL}

The Supplementary Material for this article can be found online at: https://www.frontiersin.org/articles/10.3389/fgene.2019.00645/ full\#supplementary-material

TABLE S1 | Oligonucleotide sequences used in pyrosequencing.

TABLE S2 | Oligonucleotide sequences and conditions for PCR and qPCR analyses.

TABLE S3 | Contingency tables, odds ratios (ORs), 95\% confidence intervals, and $p$-values.

FIGURE S1 | Distribution of DNA bases on methylation and AGO4-binding sites.

FIGURE S2 | Distribution of AGO4-binding sites on gene promoters.

FIGURE S3 | Proving of AGO4-binding genes.

FIGURE S4 | Confirmation of AGO4 protein associated to methylation level in AGO4-binding genes, independently function to DNA methyltransferase (DNMT).

FIGURE S5 | Recovery of methylation level in some gene-containing AGO4binding sites, in concordance with the presence of the AGO4 proteins after withdrawal of 5'-azacytidine.

FIGURE S6 | Tetracycline (Tet) (the first panel), and 5'-azacytidine and combined tetracycline and 5'-azacytidine treatment (the second panel) in scramble shRNAtransfected HEK293 cells.

FIGURE S7 | AGO4 protein expression in AGO4 plasmid and scramble shRNAtransfected and -untransfected HEK293 cells at $48 \mathrm{~h}$ after transfection. 
Chen, T., and Li, E. (2006). DNA methylation regulates genomic imprinting, $\mathrm{X}$ inactivation, and gene expression during mammalian development. in Gene Express Regulation, Springer, Switzerland 377-391. doi: 10.1007/978-0-387-40049-5_23

Chen, L., Dahlstrom, J. E., Lee, S.-H., and Rangasamy, D. (2012). Naturally occurring endo-siRNA silences LINE-1 retrotransposons in human cells through DNA methylation. Epigenetics 7 (7), 758-771. doi: 10.4161/ epi.20706

Chu, Y., Yue, X., Younger, S. T., Janowski, B. A., and Corey, D. R. (2010). Involvement of argonaute proteins in gene silencing and activation by RNAs complementary to a non-coding transcript at the progesterone receptor promoter. Nucleic Acids Research 38 (21), 7736-7748. doi: 10.1093/nar/gkq648

Colella, S., Shen, L., Baggerly, K. A., Issa, J. P. J., and Krahe, R. (2003). Sensitive and quantitative universal Pyrosequencing ${ }^{\text {TM }}$ methylation analysis of $\mathrm{CpG}$ sites. Biotechniques 35 (1), 146-151. doi: 10.2144/03351md01

Copolovici, D. M., Langel, K., Eriste, E., and Langel, U. (2014). Cell-penetrating peptides: design, synthesis, and applications. ACS Nano 8 (3), 1972-1994. doi: $10.1021 / \mathrm{nn} 4057269$

De, N., and MacRae, I. J. (2011). Purification and assembly of human argonaute, dicer, and TRBP complexes. In: Hobman T., Duchaine T. (eds) Argonaute Proteins. Methods in Molecular Biology (Methods and Protocols). 725, 107-119. doi: 10.1007/978-1-61779-046-1_8

Fedoriw, A., Mugford, J., and Magnuson, T. (2012). Genomic imprinting and epigenetic control of development. Cold Spring Harb. Perspect. Biol. 4 (7), a008136. doi: 10.1101/cshperspect.a008136

Fuks, F., Burgers, W. A., Brehm, A., Hughes-Davies, L., and Kouzarides, T. (2000). DNA methyltransferase Dnmtl associates with histone deacetylase activity. Nat. Genet. 24 (1), 88-91. doi: 10.1038/71750

Gaj, T., Gersbach, C. A., and Barbas, C. F., III (2013). ZFN, TALEN, and CRISPR/ Cas-based methods for genome engineering. Trends Biotechnol. 31 (7), 397405. doi: 10.1016/j.tibtech.2013.04.004

Hadjiargyrou, M., and Delihas, N. (2013). The intertwining of transposable elements and non-coding RNAs. Int. J. Mol. Sci. 14 (7), 13307-13328. doi: 10.3390/ijms140713307

Hauptmann, J., Kater, L., Löffler, P., Merkl, R., and Meister, G. (2014). “Generation of catalytic human Ago4 identifies structural elements important for RNA cleavage. RNA20 (10), 1532-1538. doi: 10.1261/rna.045203.114

He, X.-J., Hsu, Y.-F., Zhu, S., Wierzbicki, A. T., Pontes, O., Pikaard, C. S., et al. (2009). An effector of RNA-directed DNA methylation in Arabidopsis is an ARGONAUTE 4-and RNA-binding protein. Cell 137 (3), 498-508. doi: 10.1016/j.cell.2009.04.028

Hegge, J. W., Swarts, D. C., and van der Oost, J. (2018). Prokaryotic Argonaute proteins: novel genome-editing tools? Nat. Rev. Microbiol. 16 (1), 5. doi: 10.1038/nrmicro.2017.73

Hollister, J. D., and Gaut, B. S. (2009). Epigenetic silencing of transposable elements: a trade-off between reduced transposition and deleterious effects on neighboring gene expression. Genome Res. 19 (8), 1419-1428. doi: 10.1101/ gr.091678.109

Huang, L., Jones, A. M, Searle, I., Patel, K., Vogler, H., Hubner, N. C., et al. (2009). An atypical RNA polymerase involved in RNA silencing shares small subunits with RNA polymerase II. Nat. Struct. Mol. Biol. 16 (1), 91. doi: 10.1038/ nsmb.1539

Jones, P. A., and Takai, D. (2001). The role of DNA methylation in mammalian epigenetics. Science 293 (5532), 1068-1070. doi: 10.1126/science.1063852

Ketting, R. F. (2011). The many faces of RNAi. Dev. Cell 20 (2), 148-161. doi: 10.1016/j.devcel.2011.01.012

Khavari, D. A., Sen, G. L., and Rinn, J. L. (2010). DNA methylation and epigenetic control of cellular differentiation. Cell Cycle 9 (19), 3880-3883. doi: 10.4161/ cc.9.19.13385

Khorshid, M., Rodak, C., and Zavolan, M. (2010). CLIPZ: a database and analysis environment for experimentally determined binding sites of RNA-binding proteins. Nucleic Acids Research 39 (suppl_1), D245-D252. doi: 10.1093/nar/ gkq940

Kim, D. H., Villeneuve, L. M., Morris, K. V., and Rossi, J. J. (2006). Argonaute-1 directs siRNA-mediated transcriptional gene silencing in human cells. Nat. Struct. Mol. Biol. 13 (9), 793. doi: 10.1038/nsmb1142

Kitkumthorn, N., and Mutirangura, A. (2011). Long interspersed nuclear element-1 hypomethylation in cancer: biology and clinical applications. Clin. Epigenetics 2 (2), 315. doi: 10.1007/s13148-011-0032-8
Komashko, V. M., and Farnham, P. J. (2010). 5-azacytidine treatment reorganizes genomic histone modification patterns. Epigenetics 5 (3), 229-240. doi: 10.4161/epi.5.3.11409

Lahmy, S., Pontier, D., Bies-Etheve, N., Laudié, M., Feng, S., Jobet, E., et al. (2016). Evidence for ARGONAUTE4-DNA interactions in RNA-directed DNA methylation in plants. Genes Dev. 30 (23), 2565-2570. doi: 10.1101/gad.289553.116

Liu, X. S., Wu, H., Ji, X., Stelzer, Y., Wu, X., Czauderna, S., et al. (2016). Editing DNA methylation in the mammalian genome. Cell 167 (1), 233-247. e17. doi: 10.1016/j.cell.2016.08.056

Livak, K. J., and Schmittgen, T. D. (2001). Analysis of relative gene expression data using real-time quantitative PCR and the 2- DDCT method. Methods 25 (4), 402-408. doi: 10.1006/meth.2001.1262

Madani, F., Lindberg, S., Langel, Ü., Futaki, S., and Gräslund, A. (2011). Mechanisms of cellular uptake of cell-penetrating peptides. J. Biophys. 2011, 10. doi: 10.1155/2011/414729

Matranga, C., Tomari, Y., Shin, C., Bartel, D. P., and Zamore, P. D. (2005). Passenger-strand cleavage facilitates assembly of siRNA into Ago2-containing RNAi enzyme complexes. Cell 123 (4), 607-620. doi: 10.1016/j.cell.2005.08.044

Moazed, D. (2009). Small RNAs in transcriptional gene silencing and genome defence. Nature 457 (7228), 413. doi: 10.1038/nature07756

Modzelewski, A. J., Holmes, R. J., Hilz, S., Grimson, A., and Cohen, P. E. (2012). AGO4 regulates entry into meiosis and influences silencing of sex chromosomes in the male mouse germline. Dev. Cell 23 (2), 251-264. doi: 10.1016/j.devcel.2012.07.003

Morris, K. V. (2008). "RNA-mediated transcriptional gene silencing in human cells." in Rna Interference, Springer, Switzerland 211-224. doi: 10.1007/978-3540-75157-1_10

Morris, K. V., Chan, S. W.-L., Jacobsen, S. E., and Looney, D. J. (2004). Small interfering RNA-induced transcriptional gene silencing in human cells. Science 305 (5688), 1289-1292. doi: 10.1126/science.1101372

Muangsub, T., Samsuwan, J., Tongyoo, P., Kitkumthorn, N., and Mutirangura, A. (2014). Analysis of methylation microarray for tissue specific detection. Gene 553 (1), 31-41. doi: 10.1016/j.gene.2014.09.060

Mutirangura, A. (2019). "A Hypothesis to Explain How the DNA of Elderly People Is Prone to Damage: Genome-Wide Hypomethylation Drives Genomic Instability in the Elderly by Reducing Youth-Associated Gnome-Stabilizing DNA Gaps." in Epigenetics (IntechOpen) IntechOpen, London, United Kingdom. doi: 10.5772/ intechopen. 83372

Patchsung, M., Settayanon, S., Pongpanich, M., Mutirangura, D., Jintarith, P., and Mutirangura, A. (2018). Alu siRNA to increase Alu element methylation and prevent DNA damage. Epigenomics 10 (2), 175-185. doi: 10.2217/epi-2017-0096

Qi, Y., He, X., Wang, X.-J., Kohany, O., Jurka, J., and Hannon, G. J. (2006). Distinct catalytic and non-catalytic roles of ARGONAUTE4 in RNA-directed DNA methylation. Nature 443 (7114), 1008. doi: 10.1038/nature05198

Rerkasem, K., Rattanatanyong, P., Rerkasem, A., Wongthanee, A., Rungruengthanakit, K., Mangklabruks, A., et al. (2015). Higher Alu methylation levels in catch-up growth in twenty-year-old offsprings. PloS one 10 (3), e0120032. doi: 10.1371/journal.pone.0120032

Sambrook, J. (1989). Isolation of DNA from mammalian cells:protocol I. Molecular cloning. Lab. Manual, 9.16-9.19.

Sasaki, T., Shiohama, A., Minoshima, S., and Shimizu, N. (2003). Identification of eightmembers of the Argonaute family in the human genome. Genomics 82 (3), 323-330. doi: 10.1016/S0888-7543(03)00129-0

Schürmann, N., Trabuco, L. G., Bender, C., Russell, R. B., and Grimm, D. (2013). Molecular dissection of human Argonaute proteins by DNA shuffling. Nat. Struct. Mol. Biol. 20 (7), 818. doi: 10.1038/nsmb.2607

Stresemann, C., and Lyko, F. (2008). Modes of action of the DNA methyltransferase inhibitors azacytidine and decitabine. Int. J. Cancer 123 (1), 8-13. doi: 10.1002/ ijc. 23607

Su, H., Trombly, M. I., Chen, J., and Wang, X. (2009). Essential and overlapping functions for mammalian Argonautes in microRNA silencing. Genes Dev. 23 (3), 304-317. doi: 10.1101/gad.1749809

Swarts, D. C., Makarova, K., Wang, Y., Nakanishi, K., Ketting, R. F., Koonin, E. V., et al. (2014). The evolutionary journey of Argonaute proteins. Nature Structural and Molecular Biology 21 (9), 743. doi: 10.1038/nsmb.2879

Tang, Y., Gao, X.-D., Wang, Y., Yuan, B.-F., and Feng, Y.-Q. (2012). Widespread existence of cytosine methylation in yeast DNA measured by gas chromatography/ mass spectrometry. Anal. Chem. 84 (16), 7249-7255. doi: 10.1021/ac301727c 
Turchinovich, A., Surowy, H. M., Tonevitsky, A. G., and Burwinkel, B. (2016). Interference in transcription of overexpressed genes by promoter-proximal downstream sequences. Sci. Rep. 6, 30735. doi: 10.1038/srep30735

Valdmanis, P. N., Gu, S., Schüermann, N., Sethupathy, P., Grimm, D., and Kay, M. A. (2011). Expression determinants of mammalian argonaute proteins in mediating gene silencing. Nucleic Acids Research 40 (8), 3704-3713. doi: 10.1093/nar/gkr1274

Vannini, A., and Cramer, P. (2012). Conservation between the RNA polymerase I, II, and III transcription initiation machineries. Mol. Cell 45 (4), 439-446. doi: 10.1016/j.molcel.2012.01.023

Vojta, A., Dobrinić, P., Tadić, V., Bočkor, L., Korać, P., Julg, B., et al. (2016). Repurposing the CRISPR-Cas9 system for targeted DNA methylation. Nucleic Acids Research 44 (12), 5615-5628. doi: 10.1093/nar/gkw159

Wan, J., Oliver, V. F., Wang, G., Zhu, H., Zack, D. J., Merbs, S. L., et al. (2015). Characterization of tissue-specific differential DNA methylation suggests distinct modes of positive and negative gene expression regulation. BMC Genomics 16 (1), 49. doi: 10.1186/s12864-015-1271-4

Wassenegger, M., Heimes, S., Riedel, L., and Sänger, H. L. (1994). RNA-directed de novo methylation of genomic sequences in plants. Cell 76 (3), 567-576. doi: 10.1016/0092-8674(94)90119-8

Xie, M., and Yu, B. (2015). siRNA-directed DNA methylation in plants. Curr. Genomics 16 (1), 23-31. doi: 10.2174/1389202915666141128002211

Yang, N., and Kazazian, H. H., Jr. (2006). L1 retrotransposition is suppressed by endogenously encoded small interfering RNAs in human cultured cells. Nat. Struct. Mol. Biol. 13 (9), 763. doi: 10.1038/nsmb1141
Ye, R., Wang, W., Iki, T., Liu, C., Wu, Y., Ishikawa, M., et al. (2012). Cytoplasmic assembly and selective nuclear import of Arabidopsis Argonaute4/siRNA complexes. Mol. Cell. 46 (6), 859-870. doi: 10.1016/j.molcel.2012.04.013

Zhang, H., Lang, Z., and Zhu, J.-K. (2018). Dynamics and function of DNA methylation in plants. Nat. Rev. Mol. Cell Biol., 19 (8), 489-506. doi: 10.1038/ s41580-018-0016-Z

Zilberman, D., Cao, X., and Jacobsen, S. E. (2003). ARGONAUTE4 control of locus-specific siRNA accumulation and DNA and histone methylation. Science 299 (5607), 716-719. doi: 10.1126/science.1079695

Zilberman, D., Cao, X., Johansen, L. K., Xie, Z., Carrington, J. C., and Jacobsen, S. E. (2004). Role of Arabidopsis ARGONAUTE4 in RNA-directed DNA methylation triggered by inverted repeats. Curr. Biol. 14 (13), 1214-1220. doi: $10.1016 /$ j.cub.2004.06.055

Conflict of Interest Statement: The authors declare that the research was conducted in the absence of any financial relationships that could be construed as a potential conflict of interest.

Copyright (c) 2019 Chalertpet, Pin-on, Aporntewan, Patchsung, Ingrungruanglert, Israsena and Mutirangura. This is an open-access article distributed under the terms of the Creative Commons Attribution License (CC BY). The use, distribution or reproduction in other forums is permitted, provided the original author(s) and the copyright owner(s) are credited and that the original publication in this journal is cited, in accordance with accepted academic practice. No use, distribution or reproduction is permitted which does not comply with these terms. 